\title{
New axis in hypertension
}

\section{By Kai-Jye Lou, Staff Writer}

U.S. and European researchers have found that deleting the prostaglandin F receptor can lower both blood pressure and atherosclerotic plaque formation in mice. ${ }^{1}$ Now that the receptor has been shown to be involved in the renin-angiotensin system, it offers a new way to attack a pathway that has already yielded multiple marketed drugs.

Depression of the renin-angiotensin system (RAS) is known to decrease systemic blood pressure and slow atherogenesis, the formation of atherosclerotic plaques. ${ }^{2}$ Although signaling through the prostaglandin $\mathrm{E}_{2}$ receptor (PTGER4; $\mathrm{PGE}_{2}$ ) and the prostacyclin receptor (PTGIR; IP; PGI2) is known to modulate this pathway, ${ }^{3,4}$ the role of the prostaglandin F receptor (PTGFR; FP) has been less clear. Indeed, FP is the least studied of the group, despite the long-time use of its ligand, prostaglandin $\mathrm{F}_{2 \alpha}\left(\mathrm{PGF}_{2 \alpha}\right)$, for inducing labor.

In The Proceedings of the National Academy of Sciences, a group led by Garret FitzGerald reported that FP signaling also can modulate blood pressure, atherogenesis and signaling in the renin-angiotensin system. FitzGerald is director of the Institute for Translational Medicine and Therapeutics at the University of Pennsylvania and chair of the Department of Pharmacology.

FitzGerald and colleagues at the University of Southern Denmark showed that $\mathrm{FP}^{-/-}$mice had significantly lower resting systolic blood pressure than wild-type controls $(p<0.05)$. The $\mathrm{FP}^{-/-}$mice also had significantly lower plasma renin, angiotensin and aldosterone concentrations than wild-type controls $(p<0.05)$. Finally, $\mathrm{FP}^{-/-}$hyperlipidemic mice had less formation of atherosclerotic lesions than controls that expressed FP.

The physiological effects of knocking out FP were notable because researchers did not detect the receptor in the large blood vessels of normal mice and in atherosclerotic lesions of hyperlipidemic mice. Instead, they found that the receptor was expressed in kidney cells.

"To our surprise, deletion of FP reduced blood pressure and retarded atherogenesis despite the absence of detectable receptor expression in large blood vessels like the aorta or in atherosclerotic lesions in the mouse," said FitzGerald. "Here, the effect of FP deletion coincides with disruption of the renin-angiotensin system and the effect seems focused on the kidney."

"The fact that prostaglandin $\mathrm{F}_{2 \alpha}$ and FP can regulate the reninangiotensin system is most interesting and unexpected," said Richard Breyer, professor of medicine, biochemistry and pharmacology at the Vanderbilt School of Medicine. "The really novel finding is that FP activation appears to affect the renin-angiotensin system in terms of renin secretion, which is really not what one would expect from this receptor based on its signal transduction pathway." (See Figure 1, "Regulating blood pressure and atherogenesis through the renin-angiotensin system.")

Breyer was referring to the fact that FitzGerald showed that FP doesn't increase expression of cyclic adenosine monophosphate (cAMP) in renin-producing cells, in contrast to the action of the other two prostaglandin receptors-PTGER4 and PGI2. Expression of cAMP stimulates renin expression and secretion.

To show this effect, FitzGerald used Xalatan latanoprost, an FP agonist marketed by Pfizer Inc. to decrease intraocular pressure in glaucoma.

\section{Another axis of control}

There are three main types of approved hypertension drugs that modulate the renin-angiotensin system: angiotensin-converting enzyme (ACE) inhibitors, angiotensin receptor blockers and direct renin inhibitors. The latter is the newest class, with only one marketed drug, Tekturna/Rasilez aliskiren from Novartis AG.

Despite these options, many patients taking antihypertensive drugs still fail to achieve adequate blood pressure control.

"In the U.S., the percentage of patients with hypertension that achieve blood pressure control is in the $30-40 \%$ range," said Thomas Coffman, professor of medicine, cell biology and immunology and chief of nephrology at Duke University School of Medicine and Durham VA Medical Center. "One of the problems is that we don't have enough blood pressure-lowering drugs."

"The real issue here is to develop drugs that can be combined with existing ones," FitzGerald told SciBX. "Here, we show that although FP deletion affects the renin-angiotensin system, it does so in a manner distinct from that of direct renin inhibitors."

Raymond Harris Jr., director of the Division of Nephrology and professor of medicine at Vanderbilt, agreed that an FP antagonist could complement current antihypertensive drugs. "One of the issues with using ACE inhibitors and angiotensin receptor blockers is that patients get a compensatory increase in renin production. Targeting FP could theoretically be a way to decrease this production," he said.

Harris added that it will be important to demonstrate whether antagonizing FP produces an effect that is additive with other inhibitors of the renin-angiotensin system.

Breyer, Coffman and Harris all wanted to see additional data to elucidate the precise mechanism of FP. "It was not clear whether or not the observed effects in mice occurred primarily through the reninangiotensin system," said Coffman.

Coffman noted that the kidney plays a major role in regulating blood pressure and that FP is expressed in multiple types of kidney cells, including cells that are separate from the renin-angiotensin system. As a result, he said, a key question is whether targeting FP can lower blood pressure via pathways independent of the reninangiotensin system.

FitzGerald said additional FP-mediated pathways may indeed 
Figure 1. Regulating blood pressure and atherogenesis through the renin-angiotensin system. Data published in The Proceedings of the National Academy of Sciences suggest that prostaglandin $\mathrm{F}_{2 \alpha}\left(\mathrm{PGF}_{2 \alpha}\right)$ signaling via the prostaglandin $\mathrm{F}$ receptor (FP; PTGFR) could regulate blood pressure and the formation of atherosclerotic plaques. ${ }^{1}$ Researchers showed that deletion of FP decreased renin mRNA expression in the kidney, thereby decreasing renin-angiotensin system (RAS) signaling.

In juxtaglomerular granular cells in the kidney, activation of FP with a $\mathrm{PGF}_{2 \alpha}$ agonist [1a] stimulates renin secretion [1b]. Renin then activates the RAS by converting angiotensinogen to angiotensin I [2a]. RAS activation leads to higher blood pressure via angiotensin II-the oligopeptide both acts as a potent vasoconstrictor of arterioles and causes the release of aldosterone, which in turn increases the reabsorption of $\mathrm{H}_{2} \mathrm{O}$ and sodium in kidney tubules [2b]. Excessive renin secretion can result in chronic RAS activation, leading to hypertension and atherosclerosis.

A number of antihypertensives that target the RAS are already on the market. Selected drugs are indicated.

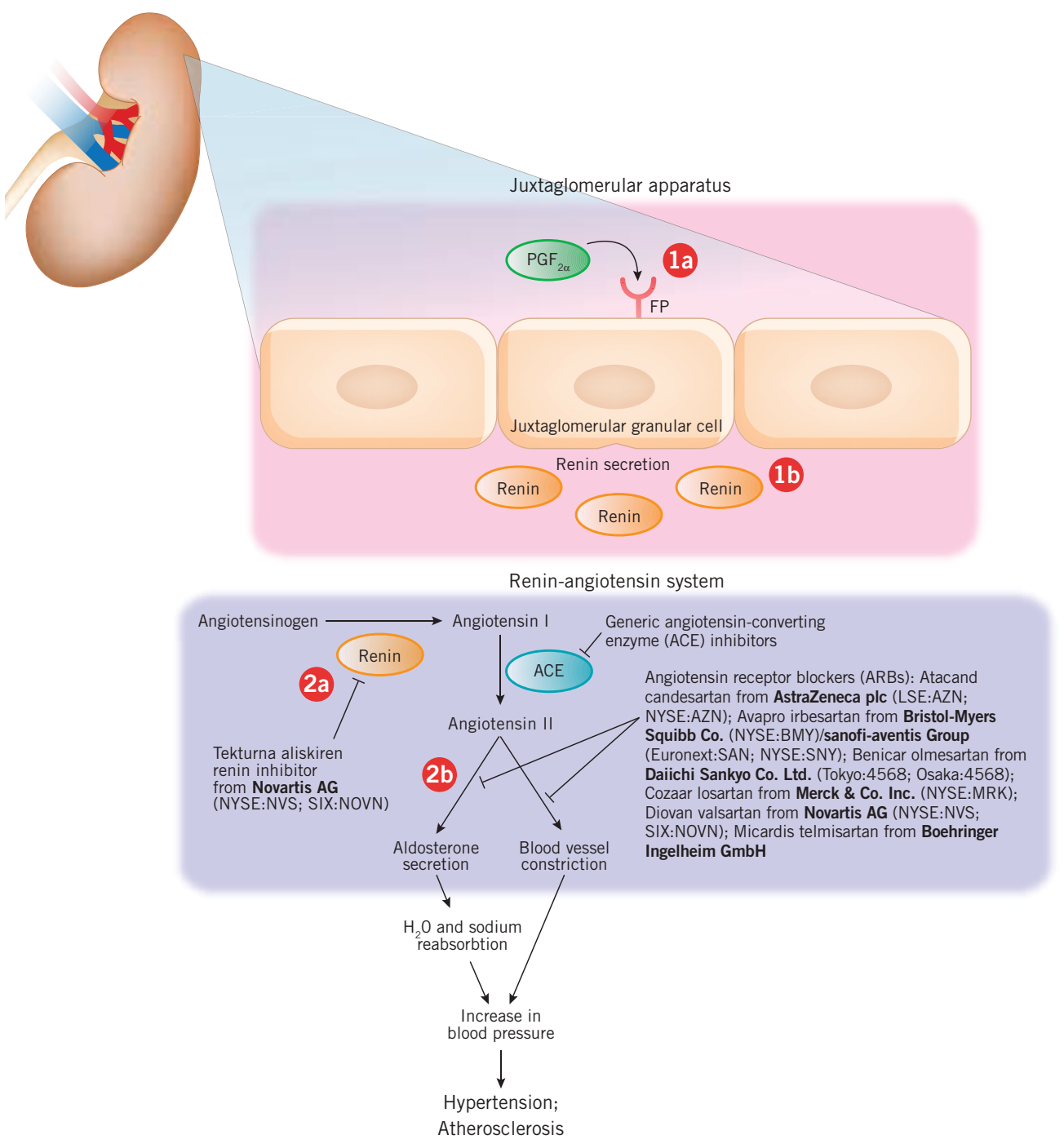

be responsible for the observed decreases in blood pressure and atherogenesis. He added that it remains unclear whether the decrease in atherogenesis from FP deletion occurs primarily through reductions in blood pressure or via a different mechanism.

Going forward, FitzGerald said his group needs to replicate the PNAS results with small molecule inhibitors of FP and extend the findings to other models of atherosclerosis and hypertension. He also wants to use pharmacological probes to see if antagonizing the receptor will induce regression of established atherosclerosis.

"If these results are promising, we might then be able to move rapidly into humans," said FitzGerald, who noted that "FP agonists are welltolerated" when locally delivered and are approved to treat glaucoma. "This both provides us with a nice scaffold for building antagonists and gives us some nice clues about translation," he said.

FitzGerald added that his group also needs to determine how deletion of FP alters renin release and how much this actually contributes to the effects on blood pressure and atherosclerosis.
A patent has been filed covering the use of $\mathrm{FP}$ antagonists in vascular and metabolic indications. The work is not yet available for licensing.

Lou, K.-J. SciBX 2(18); doi:10.1038/scibx.2009.731

Published online May 7, 2009

\section{REFERENCES}

1. Yu, Y. et al. Proc. Natl. Acad. Sci. USA; published online April 22, 2009; doi:10.1073/pnas.0811834106

Contact: Garret A. FitzGerald, University of Pennsylvania, Philadelphia, Pa. e-mail: garret@exchange.upenn.edu

2. Hammoud, R.A. et al. Vasc. Health Risk Manag. 3, 937-945 (2007)

3. Fujino, T. et al. J. Clin. Invest. 114, 805-812 (2004)

4. Friis, U.G. et al. Am. J. Physiol. Renal Physiol. 289, F989-F997 (2005)

COMPANIES AND INSTITUTIONS MENTIONED

Duke University School of Medicine, Durham, N.C.

Durham VA Medical Center, Durham, N.C.

Novartis AG (NYSE:NVS; SIX:NOVN), Basel, Switzerland

Pfizer Inc. (NYSE:PFE), New York, N.Y.

University of Southern Denmark, Odense, Denmark

University of Pennsylvania, Philadelphia, Pa.

Vanderbilt School of Medicine, Nashville, Tenn. 